\title{
Fuzzy Logic in Mitochondrial Locomotion
}

\author{
A review of: Delettre C, Lenaers G, Griffoin J-M, Gigarel N, Lorenzo C, Belenguer P, Pelloquin L, Grosgeorge J, \\ Turc-Carel C, Perret E, Astarie-Dequeker C, Lasquellec L, Arnaud B, Ducommun B, Kaplan J, Hamel CP 2000 \\ Nuclear gene OPA1, encoding a mitochondrial dynamin-related protein, is mutated in dominant optic atrophy. Nature \\ Genetics 26:207-210 Alexander C, Votruba M, Pesch UEA, Thiselton DL, Mayer S, Moore A, Rodriguez M, Kellner \\ U, Leo-Kottler B, Auburger G, Bhattacharya SS, Wissinger B 2000 OPA1, encoding a dynamin-related GTPase, is \\ mutated in autosomal dominant optic atrophy linked to chromosome 3q28. Nature Genetics 26:211-215
}

$\mathrm{T}^{\mathrm{s}}$ he term 'mitochondria' was coined by the German physician Karl Benda (1857-1933) and is a combination of the Greek mitos 'a thread' + chondros 'a cereal grain'. Since mitochondria are now widely believed to be pleomorphic, the combination of these terms is fitting since they can either resemble the isolated rice-grain form depicted in many textbooks or they can be fused to form a continuous threadlike reticulum that forms a threedimensional branching structure within the cell. How mitochondria go from one form to the other and how they move around the cell have been the subject of investigation in recent years, but despite descriptions of abnormal morphology in patients with neuromuscular disease, no-one had shown that a failure of these systems could result in human disease.

The fuzzy onions (FZO) gene was first described in mutant fruit flies which displayed an onion-like morphology in the mitochondria of spermatids because the mutation prevented mitochondria from fusing together (1). Experiments in yeast done in response to the isolation of the FZO gene in Drosophila showed that the equivalent $\mathrm{S}$. cerevisiae gene was required for mitochondrial fusion. In both the Drosophila and yeast cases, mutation of the FZO gene resulted in a punctate rather than fused reticulate mitochondrial morphology. Mutations in another mitochondrial protein, the dynamin-related protein Dnmlp, restored normal mitochondrial shape and distribution in Fzolp mutant yeast, so it appeared there were two antagonist proteins, Fzolp and Dnmlp which opposed

\section{BRIAN H. RoBINSON}

each other's actions, the former promoting fusion and the latter promoting divi$\operatorname{sion}(2,3)$. Another dynamin related protein, Drplp (which is $46 \%$ identical to Dnm1p) was also shown to have dominant effect, causing perinuclear aggregation of mitochondria in cells (4). Mitochondria are also capable of organelle movement which seems to be dependent on ATP-dependent propulsion along microtubules catalyzed by kinesin (heavy chain) (5).

In the October issue of Nature Genetics, a disorder of mitochondrial distribution is described in patients with Type I dominant optic atrophy (6). These patients have truncating or missense mutations in another dynamin-related protein, Opalp, which has strong homology to the yeast protein Mgm1p. The effect on morphology in patients with dominant mutations was that mitochondria appeared to be clumped in aggregates instead of being evenly distributed around the cell. That this could be seen in monocytes in a blood sample from affected patients is remarkable and emphasizes that the effect may extend to many cell and tissue types in the body.

How then do we reconcile the phenotype of optic atrophy with the mutations in a gene required for mitochondrial division and dispersion? The presentation of dominant optic atrophy consists of a late onset optic neuropathy, resembling the mtDNA encoded Leber hereditary optic neuropathy (LHON) $(6,7)$. In this latter defect there is actually a defect (albeit mild) in oxidative phosphorylation due to a mutation in the ND4 gene of a protein in complex I (NADHubiquinone oxidoreductase). It would seem that having mitochondrial maldistribution produces an almost equivalent functional symptomology. This implies that either compromised 'function' of clumped mitochondria or limitations imposed by long diffusion distances for metabolites such as ATP and ADP could lie at the result of this pathogenic mechanism. It will be interesting to see which one of these is the case, and whether more such disorders of mitochondrial morphology emerge!

1. Hales KG, Fuller MT 1997 Developmentally regulated mitochondrial fusion mediated by a conserved, novel, predicted GTPase. Cell 90:121-129

2. Sesaki H, Jensen RE 1999 Division versus fusion: Dnmlp and Fzolp antagonistically regulate mitochondrial shape. J Cell Biol 147:699-706

3. Bleazard W, McCaffery JM, King EJ, Bale S, Mozdy A, Tieu Q, Nunnari J, Shaw JM 1999 The dynamin-related GTPase Dnm1 regulates mitochondrial fission in yeast. Nat Cell Biol 1:298-304

4. Labrousse AM, Zappaterra MD, Rube DA, van der Bliek AM 1999 C. elegans dynamin-related protein DRP-1 controls severing of the mitochondrial outer membrane. Mol Cell 4:815-826

5. Tanaka Y, Kanai Y, Okada Y, Nonaka S, Takeda S, Harada A, Kirokawa N 1998 Targeted disruption of mouse conventional kinesin heavy chain, kif5B, results in abnormal perinuclear clustering of mitochondria. Cell 93:1147-1158

6. Delettre C, Lenaers G, Griffoin J-M, Gigarel N, Lorenzo C, Belenguer P, Pelloquin L, Grosgeorge J, Turc-Carel C, Perret E, Astarie-Dequeker C, Lasquellec L, Arnaud B, Ducommun B, Kaplan J, Hamel CP 2000 Nuclear gene OPA1, encoding a mitochondrial dynamin-related protein, is mutated in dominant optic atrophy. Nat Genet 26:207-210

7. Alexander C, Votruba M, Pesch UEA, Thiselton DL, Mayer S, Moore A, Rodriguez M, Kellner U, LeoKottler B, Auburger G, Bhattacharya SS, Wissinger B 2000 OPA1, encoding a dynamin-related GTPase, is mutated in autosomal dominant optic atrophy linked to chromosome 3q28. Nat Genet 26:211-215

Metabolism Research Programme

Research Institute

The Hospital for Sick Children

555 University Avenue

Toronto, Ontario M5G $1 X 8$, Canada 